\title{
Journal prospects and formation of the new advisory board
}

\author{
Luiz Fernando Ferraz da Silva
}

$\mathrm{O}$ ne hundred years later, dearly missed Arnaldo Vieira de Carvalho's advice continues to serve as an encouragement for the current generations to pursue with competence, dedication and passion the perpetuation of Revista de Medicina as a dissemination vehicle of scientific results obtained by the students of USP School of Medicine (Faculdade de Medicina da USP - FMUSP) and all over the country, seeking to adapt it to the innovation and modernities of our Era.

In this article, I will not focus on historical aspects, so brilliantly addressed by Gustavo Gameiro in the Editorial as well as by Cyro Festa and Andre Mota in the previous article, but I will aim to demonstrate, using the recent advances of Revista de Medicina in scientific and management terms, the reasons for my optimism regarding the future of this journal and its prospects.

From the scientific point of view, Revista de Medicina aims to provide the dissemination of medical students' results and scientific activities, giving them visibility in the medical literature. Throughout these 100 years, many current researchers had their first papers published by Revista de Medicina while they were still students. Through periodic and thematic issues, the journal
"...I thus ask you to accept my sincere congratulations for the success achieved by the Revista de Medicina (Journal of Medicine) and with them, my fervent wishes that the the students of this college continue to cultivate science with the same passion shown, thereby ennobling the medical profession, dignifying the School " Arnaldo Vieira de Carvalho. Revista de Medicina. 1916;1(1).

features not only articles written primarily by medical students, but also systematic reviews conducted by renowned Researchers, who are invited to write for special issues of the journal. This quality policy associated to the availability of digital versions of the journal, reducing its cost of publication and distribution also allowed the journal to be even more distributed. A unique data revealing the relevance and scope of this space is the fact that Revista de Medicina is in the leading position of scientific papers downloads among the journals listed in the USP Portal of Journals (Portal de Revistas da USP), the largest in Latin America.

Combining the opportunity of publishing for students still in college with the search for quality and scientific standards is a delicate and balanced work, performed by the journal's Board of Directors with the support of the scientific editorial board, responsible for the "peer review" of the papers. This Editorial Board, formerly comprising exclusively FMUSP full Professors and Professors Emeriti, was considerably redesigned and started performing the Advisory Board function since 2014, featuring now 31 members, Including USP faculty and Researchers connected to the Hospital das 
Clínicas/FMUSP Complex with research experience in several areas as well as Researchers from other institutions in Brazil and abroad, such as the University of Toronto, the University of Zurich and Harvard University. Among other functions, this Advisory Board is responsible for (1) guaranteeing, through technical criteria, the quality of the papers accepted by the journal; and (2) ensuring the paper review flow in an efficient and dynamic manner. The coordination of this Board, held by a USP Professor nominated by Revista de Medicina's academic Board of Directors, has the additional assignment of supporting in the selection and replacement of board members, nomination of possible eventual reviewers, and also, submit specific requests for incorporating resources (through scholarships or projects). This new Advisory Board of the journal may also contribute via suggestions forwarded to the journal's academic Board of Directors concerning (1) specific issues, (2) creation and modification of sections of the journal, in addition to its technical function of guaranteeing the final scientific quality of the issues.

In addition to the modernization and redesigning from the scientific point of view, the administrative and management restructuring of the journal, led by the Scientific Department and supported by the FMUSP Board of Directors, has been fundamental. During the last year it was possible to reorganize the administrative structure of the Journal by updating its Publishing Rules and Instructions, in order to guarantee not only the proper implementation but also the quality policy of the published papers. This strategy, combined with the implementation of the FMUSP Journal Editorial Center (Núcleo Editorial de Revistas da FMUSP), with its own physical space and human and material resources devoted to the process of managing and editing, will certainly enable not only the maintenance of the current quality policy, but its improvement in terms of periodicity and standardization/ adjustment to the rules established by different databases. In fact, the journal has already achieved its indexing to the
LILACS database (LILACS is the most important and comprehensive index of scientific and technical literature of Latin America and the Caribbean) and is seeking new indicators that may enable its indexing to other databases such as SciELO.

Based only on these recent advances, clear statements that the "passion" mentioned by Arnaldo Vieira de Carvalho, is still alive in the present generations, I consider it not to be an overestimation to trace herein some future prospects for the next years of Revista de Medicina, such as:

1. Maintenance of the lead position as a space for publishing scientific results from projects of the medical students;

2. Broadening of the databases in which the journal will be indexed;

3. Progressive increase of the quality and impact of the papers published in the journal;

4. Development of a dynamic profile, with new periodic sections covering different points of research in the academic life such as digital inclusion, academic extension, reports of cases experienced by the students, among others.

Just as every milestone in the life of an Institution, this centenary of Revista de Medicina has been acting as a point of reflection and encouragement for it to continue to seek to exceed itself in quality terms and to be also increasingly able to approach the students and their academic life, maintaining its primary role in the academic and scientific development of the country's medical students.

Only daily work will ensure that these changes are maintained and consequently that the outlined objectives and prospects are achieved. However, considering the Journal's pioneering spirit, its history and the enthusiasm of its academic publishers, our future is auspicious! 